Review Article:

\title{
The Association Between Exposure to Ambient Particulate Matter and Childhood Obesity: A Systematic Review and Meta-analysis
}

\author{
Maryam Bahreynian $^{1}$ (D), Marjan Mansourian ${ }^{2}$ (D), Nafiseh Mozaffarian ${ }^{3}$ (D), Parinaz Poursafa ${ }^{4}$ (D) Mehri Khoshhali $^{3^{*}}$ (D), Roya Kelishadi ${ }^{3}$ (D) $^{2}$
}

1. Department of Nutrition Child Growth, and Development Research Center, Research Institute for Primordial Prevention of Non-communicable Diseases, Student Research Committee, Isfahan University of Medical Sciences, Isfahan, Iran.

2. Department of Biostatistics and Epidemiology, School of Health, Isfahan University of Medical Sciences, Isfahan, Iran.

3. Department of Pediatrics, Child Growth, and Development Research Center, Research Institute for Primordial Prevention of Non-communicable Diseases, Isfahan University of Medical Sciences, Isfahan, Iran.

4. Environment Research Center, Research Institute for Primordial Prevention of Non-communicable Diseases, Isfahan University of Medical Sciences, Isfahan, Iran.

\begin{tabular}{|l|l}
$\begin{array}{l}\text { Use your device to scan } \\
\text { and read the article online }\end{array}$ \\
8(1):1-14. http://dx. doi. org/10. 32598/jpr. 8. 1. 1 \\
to Ambient Particulate Matter and Childhood Obesity: A Systematic Review and Meta-analysis. Journal of Pediatrics Review. 2020;
\end{tabular}

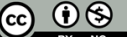

Article info:

Received: 10 Oct 2018

First Revision: 23 Feb 2019

Accepted: 09 Mar 2019

Published: 01 Jan 2020

\section{A B S TR A C T}

Context: Physical environment contamination and in particular, air pollution might cause long-term adverse effects in child growth and a higher risk of catching non-communicable diseases later in life.

Objective: This study aimed to overview the human studies on the association of exposure to ambient Particulate Matter (PM) with childhood obesity.

Data Sources: We systematically searched human studies published until March 2018 in PubMed, Scopus, Ovid, ISI Web of Science, Cochrane library, and Google Scholar databases.

Study Selection: All studies that explored the association between PM exposure and childhood obesity were assessed in the present study, and finally, 5 studies were used in the meta-analysis.

Data Extraction: Two independent researchers performed the data extraction procedure and quality assessment of the studies. The papers were qualitatively assessed by STROBE (Strengthening the Reporting of Observational studies in Epidemiology) statement checklist.

Results: The pooled analysis of PM exposure was significantly associated with increased Body Mass Index (BMI) (Fisher's z-distribution=0. 028; 95\% Cl=0. 017, 0. 038) using the fixed effects model. We also used a random-effect model because we found a significant high heterogeneity of the included studies concerning the PM $\left(I^{2}=94.4 \% ; \mathrm{P}<0.001\right)$. PM exposure was associated with increased $\mathrm{BMI}$ (Fisher's z-distribution=0. 022; 95\% $\mathrm{Cl}=-0.057,0.102$ ). However, the overall effect size was not significant, and heterogeneity of the included studies was similar to the fixed effect model.

Discussion: Our findings on the significant association between PM10 exposure and the increased BMI $(r=0.034 ; 95 \% C l=0.007,0.061)$ without heterogeneity $\left(I^{2}=16.6 \%, P=0.274\right)$ (in the studies with PM10) suggest that the PM type might account for the heterogeneity among the studies.

Conclusion: The findings indicate that exposure to ambient PM10 might have significant effects on childhood obesity.
Key Words:

Air pollution, Particulate matter, Childhood obesity, Meta-analysis

* Corresponding Author:

Mehri Khoshhali, MD.

Address: Department of Pediatrics, Child Growth and Development Research Center, Research Institute for Primordial Prevention of Non-communicable Diseases, Isfahan University of Medical Sciences, Isfahan, Iran.

Tel: +98 (311) 7925215

E-mail:m.khoshhali@yahoo.com 


\section{Context}

hildhood obesity is a growing public health problem, even in developing countries $(1,2)$. It is associated with several health complications during childhood, which will usually extend to adulthood (3). It has several underlying causes, both genetic and environmental factors $(4,5)$.

Recently, researchers have paid attention to the association between air pollution and obesity, and some studies suggest that ambient air pollution may increase the risk of catching Non-communicable Diseases (NCDs) in adults, diseases such as cardiovascular diseases, diabetes and cancer (6-8). However, little epidemiological evidence is available on the association of exposure to ambient air pollution with the development of childhood obesity (9-11). Physical environment contamination and in particular, air pollution might cause longterm adverse effects in child growth and a higher risk of developing NCDs later in life. The "Obesogenic Environment" hypothesis discusses the impact of environmental chemicals with endocrine disruption properties that can change child growth patterns and result in weight gain, obesity, and obesity-related NCDs (12).

Some previous studies reveal a positive association between exposure to Polycyclic Aromatic Hydrocarbons (PAHs) and childhood obesity $(11,13)$. A recent study conducted in China reports that long-term exposure to air pollutants, including Particulate Matter $(\mathrm{PM})_{10}, \mathrm{NO}_{2}, \mathrm{SO}_{2}$, and $\mathrm{O}_{3}$ is associated with higher risk of childhood obesity and hypertension (14). Moreover, the association of residential traffic density and roadway proximity with rapid infant weight gain and childhood obesity has been documented in some previous studies (15-18). A study on Latino children living in the US shows that higher exposure to $\mathrm{NO}_{2}$ and $\mathrm{PM}_{2}$ ${ }_{5}$ is related to higher Body Mass Index (BMI) at the age of 18 (19). However, some other studies report no association between exposure to vehicular traffic and pollutants and the risk of obesity and dyslipidemia in children $(20,21)$. Therefore, the overall evidence on obesogenic properties of air pollutants is controversial.

\section{Objectives}

Due to the high prevalence of childhood obesity, its multifactorial nature, and the importance of conducting preventive strategies, we aimed to provide a systematic review and meta-analysis on the association of exposure to ambient PM and childhood obesity.

\section{Data Sources}

We performed a systematic review and meta-analysis of human studies that explored the association between PM exposure and childhood obesity. We considered PECO as the following: Population (P): Children and adolescents; Exposure (E): PM exposure; Comparison (C) (There is no comparison between exposed and non-exposed groups because we have reported the correlations of PM exposure and $\mathrm{BMI})$; and Outcome (O): Childhood obesity (BMI).

We systematically searched human studies available on the study subject until March 2018 in PubMed, Scopus, Ovid, ISI Web of Science, Cochrane library, and Google Scholar databases. All cross-sectional and cohort studies were selected. We used the search terms of "Air Pollution" OR "Pollutants" OR "Particulate Matter" in combination with "Obesity" OR "Weight" OR "Body Mass Index" OR "BMI" OR "Overweight" OR "Cardiometabolic" OR "Metabolic Syndrome" OR "Metabolic Syndrome X" OR "Mets" OR "Adiposity" AND “Child” OR "Adolescent" OR "School-aged" OR "Youth" OR "Teenager" OR "Boy" OR "Girl" OR "Student" OR "Pediatrics" in the form of Medical Subject Headings (MeSH) and truncations. The relevant articles were examined without any language restriction.

\section{Study Selection}

After removing the duplicates, the relevant papers were selected in three phases. In the first and the second phases, titles and abstracts of papers were screened, and the irrelevant papers were excluded. In the third phase, the full texts of the remaining papers were explored carefully to select only the relevant papers. To find any additional pertinent study, the reference list of all reviews and related papers were screened as well.

The included studies had the following criteria: 1. Observational cross-sectional design; 2. Longitudinal cohort studies which report the study association; 3. Measurement of PM concentration as an index for air pollution exposure; and 4. Reporting the Odds Ratio (OR), Relative Risk (RR), and $\beta$-coefficient of PM with child obesity. In the final step, all statistics were changed to the correlation coefficient values.

\section{Data Extraction}

Two reviewers extracted the data independently using a data collection form, including the first author's name, publication year, sample size, study design, as well as 
age, exposure measurement, statistical analysis, and the variables adjusted in the analyses.

\section{1. Quality assessment}

Two independent reviewers ( $\mathrm{MB}$ and $\mathrm{MKH}$ ) evaluated the methodological quality of each study. The Strengthening the Reporting of Observational studies in Epidemiology (STROBE) checklist was used for the quality assessment of the papers. According to STROBE (22 questions), the included studies were divided into three groups of high, medium, and low-quality. The studies scored one to eight were ranked as low-quality studies, 9-16 as medium-quality ones, and 17-22 as high-quality papers. The two reviewers agreed on (80\%) of cases. The remaining discrepancies were resolved by consultation and consensus.

\section{2. Statistical analysis}

The effect sizes of RR, OR, and $\beta$-coefficient from all articles were extracted directly from the original reports. All effect sizes were transformed into ( $r$ : correlation), and Fisher z-transformation of the $r$ value was applied for the pooled analysis $(22,23)$. The potential heterogeneity across studies was evaluated using the Cochran's $Q$ test and was expressed using the $\mathrm{I}^{2}$ index. The pooled results for Fisher z-transformation were calculated by the fixed-effects model (for low heterogeneity) or the random-effects model (for high heterogeneity). Publication bias was evaluated by the Egger's and the Begg's tests. Subgroup analyses and meta-regression were performed to seek the sources of heterogeneity. The sensitivity analyses were performed by omitting one study at a time to gauge the robustness of our results. All statistical analyses were conducted in STATA V. 14. 0.

\section{Results}

We initially retrieved 4391 articles from the databases. Figure 1 represents the search results. After the initial study of the titles and abstracts, the duplicate papers were omitted, and out of 4276 papers, five articles remained. No additional references were identified through checking the reference lists of selected papers.

The main characteristics of the studies included in the systematic review are presented in Appendix 1. Overall, the studies reported data on 33825 subjects, and they were published between 2010 and 2018 .

\section{1. Meta-analysis of the correlations}

Figure 2 showed the pooled results using random effect model. It showed that PM exposure was associated with the increased BMI (Fisher-z=0. 022; 95\% Cl (-0. $057,0.102)$ ) that overall effect size was not significant and heterogeneity of the included studies was as same fixed effect model.

Table 1 presents the results of the meta-regression analysis. The univariate meta-regression analyses indicated that none of the factors, including mean age, sample size, study location (Europe, Asia, and the USA), study type (cross-sectional and cohort), and PM type (2. 5 and 10) contributed to the heterogeneity of metaanalysis ( $P>0.05$ for all).

Table 2 presents the results of subgroup analysis according to the study location, study type, and PM type. We observed significant association between $\mathrm{PM}_{10}$ exposure and the increased BMI (Fisher's $z=0.034 ; 95 \%$ $\mathrm{Cl}=0$. 007, 0. 061) with no apparent heterogeneity $\left(I^{2}=16.6 \%, P=0.274\right)$ in the studies with $\mathrm{PM}_{10}$. It suggests that the PM type may partially account for the heterogeneity among the studies on BMI (Figure 3).

Begg's test and Egger's test revealed no obvious publication bias among these studies. The P-values for these tests were higher than $0.05(P=0.661$ and 1.0 , respectively). The results of sensitivity analyses showed that with excluding the study of Fleisch AF et al. (7. 7 years), the pooled Fisher's $z$ for the subgroup $\mathrm{PM}_{2.5}$ increased. Although this change was not significant, it decreased the overall heterogeneity $\left(I^{2}=83.1 \%, P<0.001\right)$ (Figure 4).

Figure 4 Forest plot of Fisher's z values for the correlation between PM and BMI by PM type after excluding the study of Fleisch AF et al. (7. 7 years) Table 3 presents the results of converting Fisher's $z$ values into correlation values. We found a significant relationship between $\mathrm{PM}_{10}$ and $\mathrm{BMI}(\mathrm{r}=0.034, \mathrm{P}=0.015)$, but the association of $\mathrm{PM}_{2.5}$ and $\mathrm{BMI}$ was not statistically significant ( $r=0.035, P=0.606)$.

\section{Discussion}

This systematic review and meta-analysis revealed a weak positive association between ambient $\mathrm{PM}_{10}$ and child obesity. However, the results for $\mathrm{PM}_{2.5}$ was not significant. A few meta-analysis or large sample size studies have explored the association of ambient PM with adult obesity or birth weight, but with childhood obesity (24-26). 


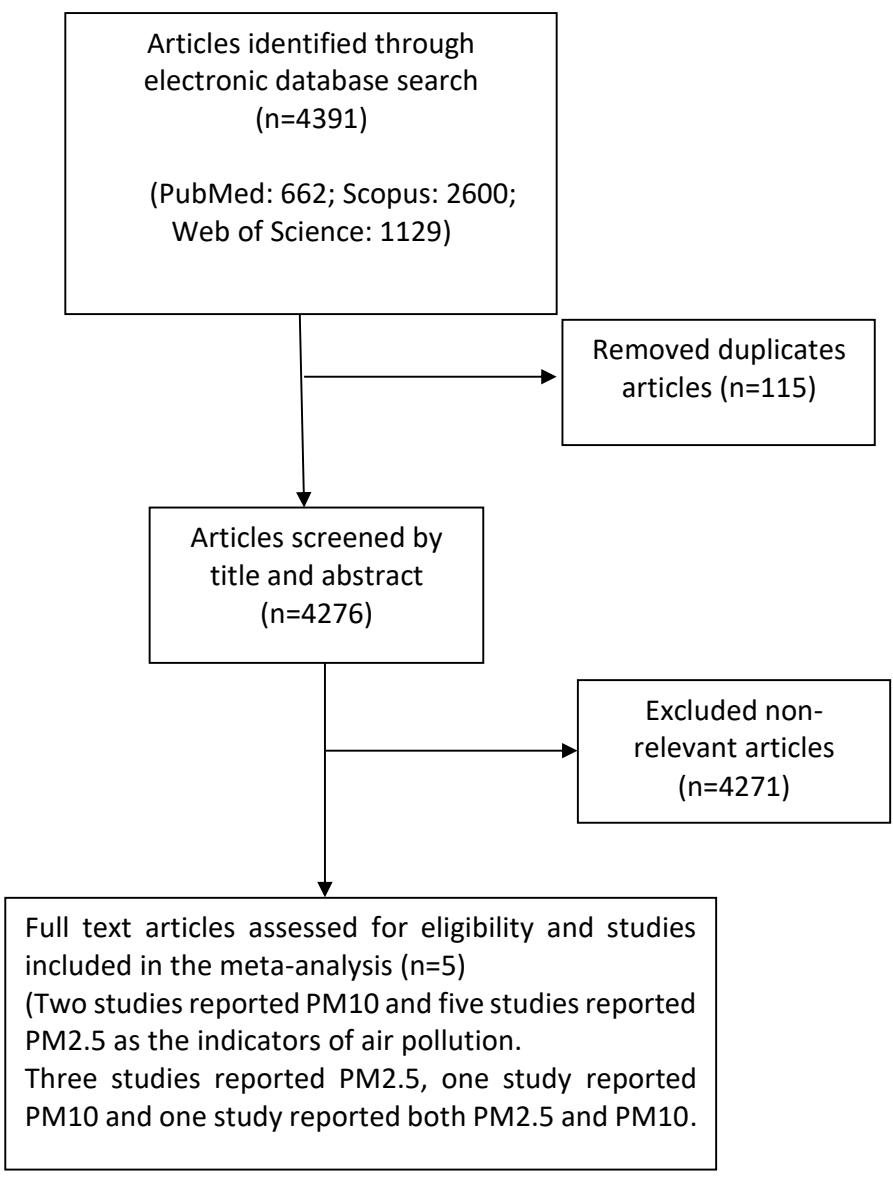

Figure 1. The flowchart of the search results

Journal of Pediatrics Review

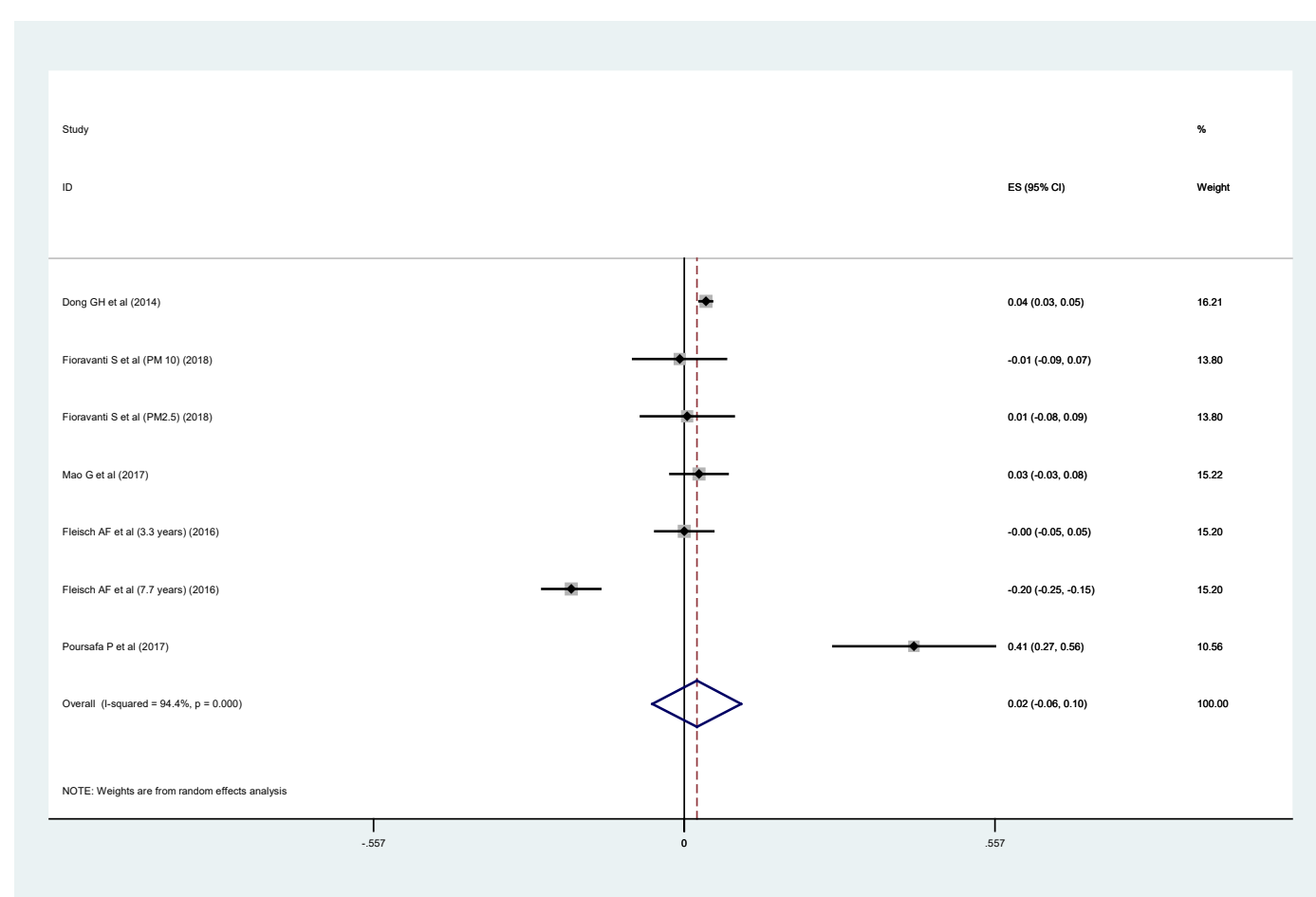

Journal of Pediatrics Review

Figure 2. Forest plot of Fisher's $z$ values indicating the correlation between PM and BMI 
Table 1. Results of meta-regression analyses for the potential source of heterogeneity

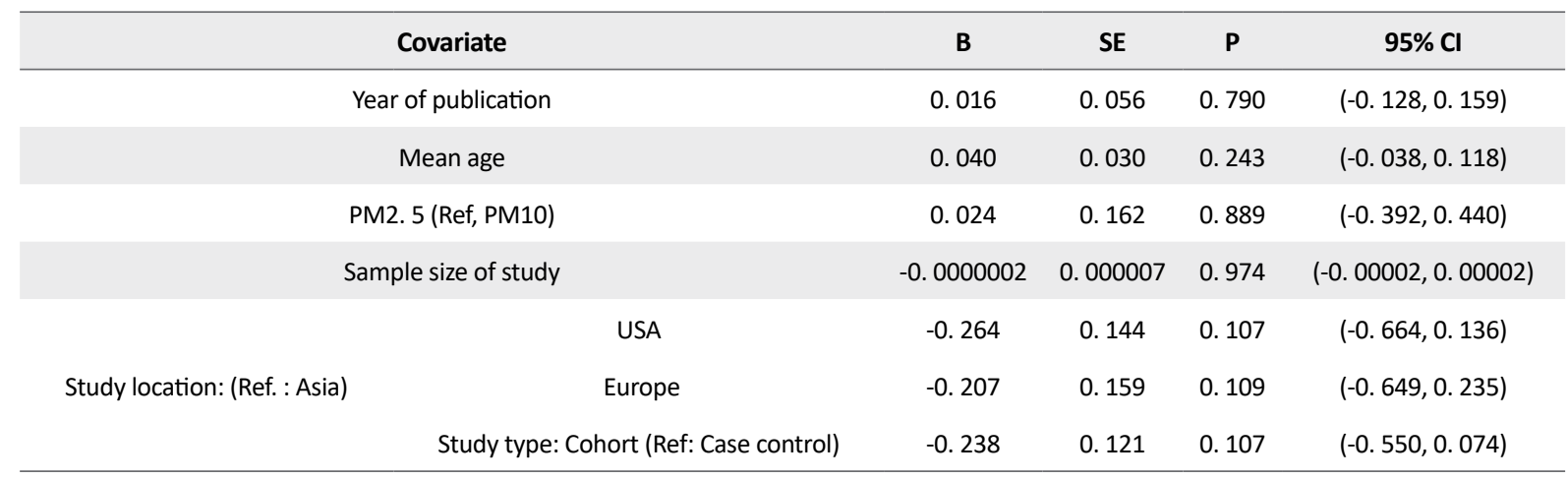

SE: Standard Error; Cl: Confidence Interval Journal of Pediatrics Review

Table 2. Results of subgroup analysis on the association between PM and BMI

\begin{tabular}{|c|c|c|c|c|c|c|}
\hline \multirow{2}{*}{ Variables } & \multirow{2}{*}{ Groups } & \multirow{2}{*}{ NO. of Study } & \multirow{2}{*}{ Effect Size (Fisher' z) 95\% Cl } & \multirow{2}{*}{$\mathbf{P}$} & \multicolumn{2}{|c|}{ Heterogeneity } \\
\hline & & & & & $I^{2}(\%)$ & $\mathbf{P}$ \\
\hline \multirow{2}{*}{ PM type } & 10 & 2 & $0.034(0.007,0.061)$ & 0.015 & 16.60 & 0.274 \\
\hline & 2.5 & 3 & $0.035(-0.099,0.169)$ & 0.606 & 95.30 & $<0.001$ \\
\hline \multirow{2}{*}{ Study type } & Cross-sectional & 2 & $0.218(-0.148,0.583)$ & 0.243 & 96.10 & $<0.001$ \\
\hline & cohort & 3 & $-0.037(-0.132,0.057)$ & 0.442 & 91.60 & $<0.001$ \\
\hline \multirow{3}{*}{ Study location } & Asia & 2 & $0.218(-0.148,0.583)$ & 0.243 & 96.10 & $<0.001$ \\
\hline & Europe & 1 & $-0.001(-0.06,0.057)$ & 0.961 & 0.00 & 0.818 \\
\hline & USA & 2 & $-0.059(-0.2,0.083)$ & 0.416 & 95.50 & $<0.001$ \\
\hline
\end{tabular}

Journal of Pediatrics Review

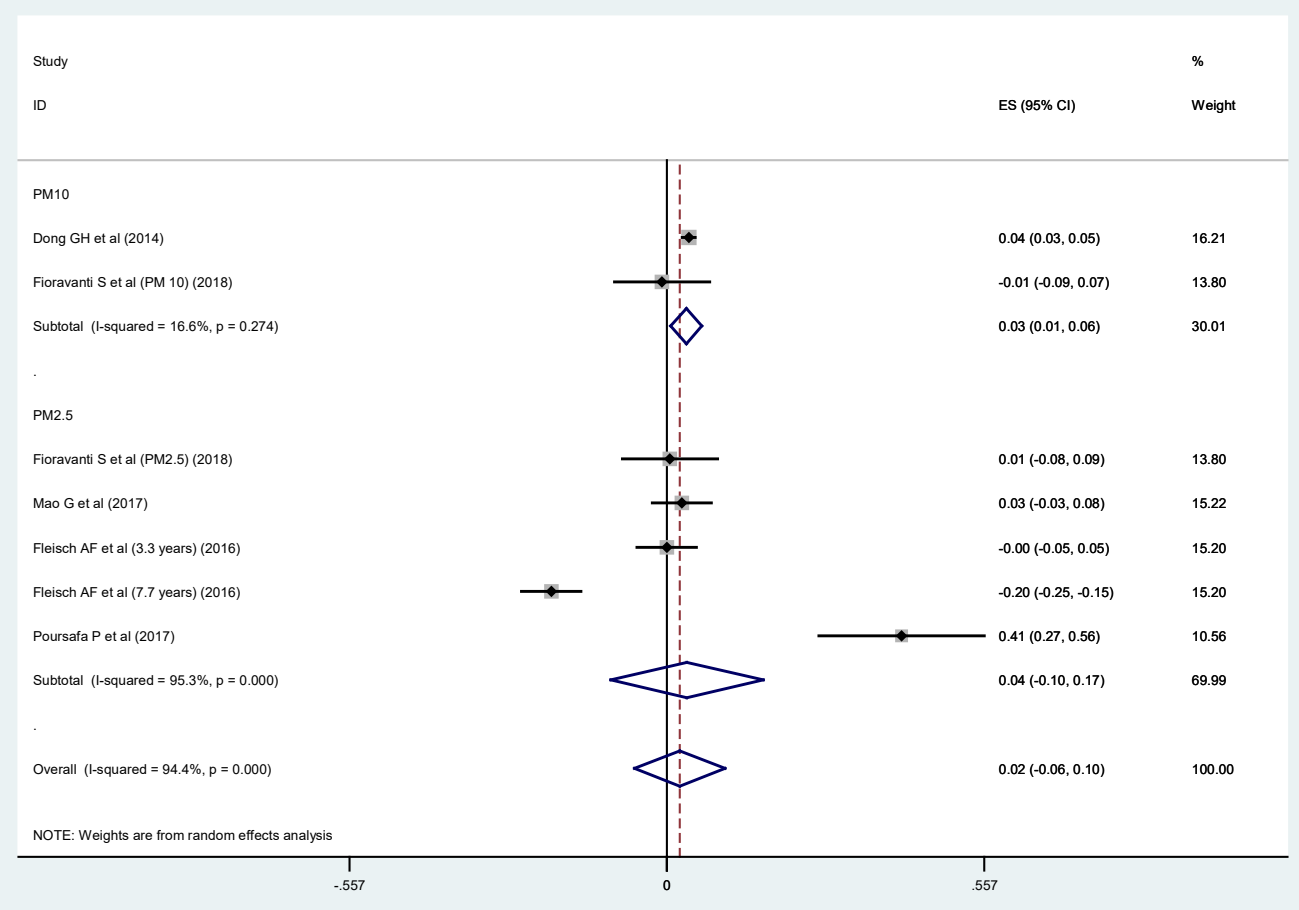

Figure 3. Forest plot of Fisher's z values indicating the correlation between PM and BMI by PM type

Journal of Pediatrics Review 


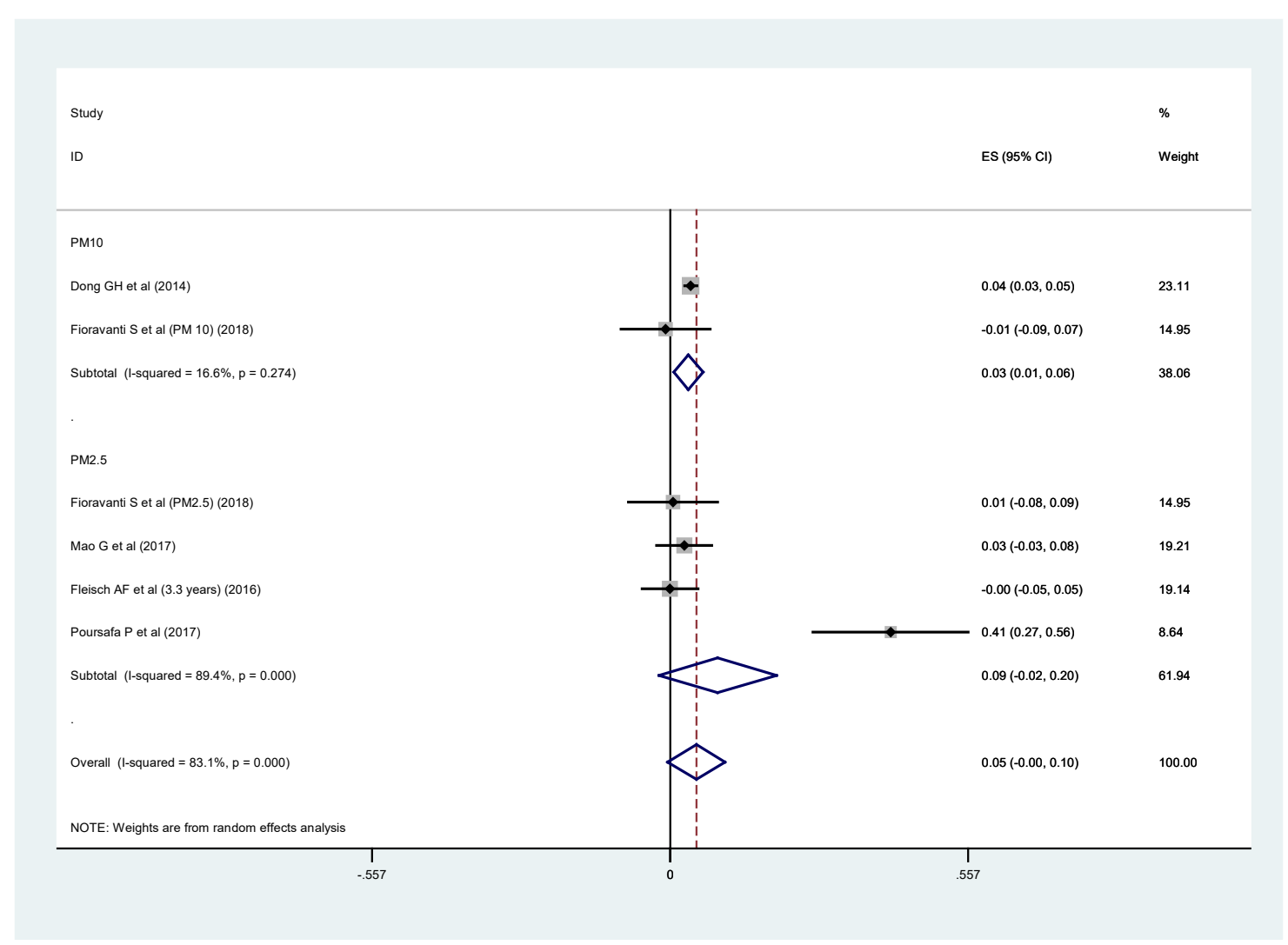

Journal of Pediatrics Review

Figure 4. Forest plot of Fisher's $z$ values, indicating the correlation between PM and BMI by PM type after excluding the study of Fleisch AF et al (7. 7 years)

Table 3. The correlation between PM exposure and BMI

\begin{tabular}{cccccccc}
\hline \multirow{2}{*}{ Variables } & \multicolumn{3}{c}{ Effect Size } & \multicolumn{3}{c}{ Heterogeneity } \\
\cline { 2 - 7 } & Pooled r & $\mathbf{9 5 \%} \mathbf{C l}$ & $\mathbf{P}$ & $\mathbf{I}^{2}$ & $\mathbf{P}$ & $\boldsymbol{\tau}^{2}$ \\
\hline PM10 & 0.034 & $(0.007,0.061)$ & 0.015 & $16.60 \%$ & 0.0002 & 0.0002 \\
PM2.5 & 0.035 & $(-0.099,0.167)$ & 0.606 & $95.30 \%$ & 0.0216 & 0.022 \\
overall & 0.022 & $(-0.057,0.102)$ & 0.579 & $94.40 \%$ & 0.0101 & 0.010 \\
\hline$\tau^{2}$ : Between-studies variance & & & & Journal of Pediatrics Review
\end{tabular}

These five studies investigated more than 33000 participants. The current literature provides conflicting results on the association between air pollution and childhood obesity $(19-21,27)$. We found a relatively weak positive relationship between exposure to $\mathrm{PM}_{10}$ and childhood BMI, consistent with most previous studies findings. Five of the seven studies included in the current meta-analysis reported the direct association of air pollution and child weight, whereas two cohort studies did not report such association $(20,21)$.
Such discrepancies among these studies results might be due to confounding factors like age, gender, ethnicity, physical activity, level of exposures, and some other factors. These findings might be confounded by heterogeneity due to multiple dispersions between studies such as study design, different techniques to measure PM concentration, the way PM levels is reported, and other various confounders which were adjusted in the analysis.

Only a few cross-sectional studies have investigated the relation of air pollution and obesity in children $(16,17,20$, 27-29). In a longitudinal study, higher exposure to $\mathrm{NO}_{2}$ and 
$\mathrm{PM}_{2.5}$ was associated with higher BMI, body fat percentage, and abdominal obesity during follow up and at the age of 18 in children who were overweight or obese at the study baseline (19). Another study conducted on overweight and obese minority youths found that higher exposures to $\mathrm{NO}_{2}$ and $\mathrm{PM}_{2.5}$ during one year before the study was not associated with obesity, but it was related to lower insulin sensitivity and higher acute insulin response to glucose, which might contribute to obesity $(19,30)$.

The mechanisms linking air pollution to obesity risk and type-2 diabetes are not entirely determined. The effects of air pollutants on immune response, oxidative stress, and insulin resistance might explain the results (31).

Air pollutants such as PM might increase the infiltration and activation of immune-competent cells, including monocyte and macrophages, in body tissues (32). Previous findings also indicated that early life exposure to $\mathrm{PM}_{2.5}$ might result in insulin resistance and obesity later in life, through $\mathrm{NAD}(\mathrm{P}) \mathrm{H}$ oxidase-derived superoxide anions, which might cause changes in adipocyte numbers and size (33).

Animal studies suggest that higher exposure to air pollutants might result in increased adipose tissue inflammation, accumulation of glucose in skeletal muscles, and therefore it might contribute to metabolic dysfunction and obesity $(34,35)$. Furthermore, previous studies indicate that long-term exposure to combustion-related air pollutants can increase systemic inflammation and oxidative stress (34).

Little information is available about the biological basis of the relationship between exposure to air pollutants and childhood obesity. There may be a potential for residual confounders, including socioeconomic status and physical activity, which can be associated with both air pollution exposure and children's weight. Therefore, residual confounding may affect the study results due to the associations of poor diet and low physical activity with child overweight and metabolic disruption. Also, these factors may be related to residential proximity to sources of air pollution $(36,37)$. For example, children living in areas with higher levels of air pollution usually belong to lower socioeconomic families who often consume higher amounts of total or saturated fats $(27,38)$.

Lack of physical activity among the children living in polluted regions (because of their parental control to restrict the children's exposure to air pollution) may be another reason for the excess weight in children. It is documented that overweight children usually have less frequent and shorter peri- ods of activities compared to their normal weight peers (39, 40). However, the findings on the associations of exposure to air pollutants and childhood obesity are unlikely to be confounded by these factors, because many of these studies had adjusted these associations for socioeconomic status, as a strong predictor of dietary intake and physical activity (36).

Furthermore, misclassification of exposure to air pollutants might have occurred with residential-based estimates of pollutant exposure, which might decrease the observed effects (41). Some studies also lack information about other potential confounders such as active and passive smoking as well as exposure to noise pollution (19). Previous studies suggest that tobacco exposure and near roadway air pollution contribute to synergistic effects on the development of child obesity (18).

The findings of the current study concerning the association of exposure to ambient PM with childhood obesity should be considered with caution. The cross-sectional design of some studies used for this meta-analysis might preclude any causality. Another limitation is the high heterogeneity between studies. Other potential risk factors like child physical activity, familial socioeconomic status, and climate conditions were not available in some studies.

\section{Conclusions}

This systematic review and meta-analysis indicate that exposure to ambient $\mathrm{PM}_{10}$ has a weak positive association with childhood obesity. This finding should be considered in future studies and preventive programs. Our results are also useful for health policymakers and health care providers to design health promotion interventions and preventive strategies. More research is needed to clarify the effect of other ambient air pollutants on child health status.

\section{Ethical Considerations}

\section{Compliance with ethical guidelines}

All ethical principles were considered in this article.

\section{Funding}

This research did not receive any specific grant from funding agencies in the public, commercial, or not-forprofit sectors.

\section{Authors contribution's}


Conceptualization, methodology, and investigation: All authors; Writing-original draft: Maryam Bahreynian; Writingreview \& editing: Maryam Bahreynian, Roya Kelishadi, Mehri Khoshhali, and Marjan Mansourian; Supervision: Roya Kelishadi and Mehri Khoshhali.

\section{Conflicts of interest}

The authors declared no conflict of interests.

\section{References}

1. Caballero B. The global epidemic of obesity: An overview. Epidemiologic Reviews. 2007; 29(1):1-5. [DOI:10. 1093/ epirev/mxm012] [PMID]

2. Kelishadi R. Childhood overweight, obesity, and the metabolic syndrome in developing countries. Epidemiologic Reviews. 2007; 29(1):62-76. [DOI:10. 1093/epirev/mxm003] [PMID]

3. Swinburn BA, Sacks G, Hall KD, McPherson K, Finegood DT, Moodie ML, et al. The global obesity pandemic: Shaped by global drivers and local environments. The Lancet. 2011; 378(9793):804-14. [DOI:10. 1016/S01406736(11)60813-1]

4. McAllister EJ, Dhurandhar NV, Keith SW, Aronne L, Barger J, Baskin M, et al. Ten putative contributors to the obesity epidemic. Critical Reviews in Food science and Nutrition. 2009; 49(10):868-913. [DOI:10. 1080/10408390903372599] [PMID] [PMCID]

5. Keith SW, Redden DT, Katzmarzyk PT, Boggiano MM, Hanlon EC, Benca RM, et al. Putative contributors to the secular increase in obesity: Exploring the roads less traveled. International Journal of Obesity. 2006; 30(11):1585-94. [DOI:10. 1038/sj. ijo. 0803326] [PMID]

6. Wang M, Beelen R, Stafoggia M, Raaschou-Nielsen O, Andersen ZJ, Hoffmann B, et al. Long-term exposure to elemental constituents of particulate matter and cardiovascular mortality in 19 European cohorts: Results from the ESCAPE and TRANSPHORM projects. Environment International. 2014; 66:97-106. [DOI:10. 1016/j. envint. 2014. 01. 026] [PMID]

7. Rajagopalan S, Brook RD. Air pollution and type 2 diabetes: Mechanistic insights. Diabetes. 2012; 61(12):3037-45. [DOI:10. 2337/db12-0190] [PMID] [PMCID]

8. de Groot P, Munden RF. Lung cancer epidemiology, risk factors, and prevention. Radiologic Clinics. 2012; 50(5):863-76. [DOI:10. 1016/j. rcl. 2012. 06. 006] [PMID]

9. Ino T, Shibuya T, Saito K, Inaba Y. Relationship between body mass index of offspring and maternal smoking during preg- nancy. International Journal of Obesity. 2012; 36(4):554-8. [DOI:10. 1038/ijo. 2011. 255] [PMID]

10. Bolton JL, Smith SH, Huff NC, Gilmour MI, Foster WM, Auten $\mathrm{RL}$, et al. Prenatal air pollution exposure induces neuroinflammation and predisposes offspring to weight gain in adulthood in a sex-specific manner. The FASEB Journal. 2012; 26(11):4743-54. [DOI:10. 1096/fj. 12-210989] [PMID]

11. Rundle A, Hoepner L, Hassoun A, Oberfield S, Freyer G, Holmes $D$, et al. Association of childhood obesity with maternal exposure to ambient air polycyclic aromatic hydrocarbons during pregnancy. American Journal of Epidemiology. 2012; 175(11):1163-72. [DOI:10. 1093/aje/kwr455] [PMID] [PMCID]

12. Thayer KA, Heindel JJ, Bucher JR, Gallo MA. Role of environmental chemicals in diabetes and obesity: A national toxicology program workshop review. Environmental Health Perspectives. 2012; 120(6):779-89. [DOI:10. 1289/ehp. 1104597] [PMID] [PMCID]

13. Kim HW, Kam S, Lee DH. Synergistic interaction between polycyclic aromatic hydrocarbons and environmental tobacco smoke on the risk of obesity in children and adolescents: The US national health and nutrition examination survey 2003-2008. Environmental Research. 2014 135:354-60. [DOI:10. 1016/j. envres. 2014. 08. 032] [PMID]

14. Dong GH, Wang J, Zeng XW, Chen L, Qin XD, Zhou Y, et al. Interactions between air pollution and obesity on blood pressure and hypertension in Chinese children Epidemiology. 2015; 26(5):740-7. [DOI:10. 1097/EDE. 0000000000000336] [PMID]

15. Fleisch AF, Rifas-Shiman SL, Koutrakis P, Schwartz JD, Kloog I, Melly S, et al. Prenatal exposure to traffic pollution: Associations with reduced fetal growth and rapid infant weight gain. Epidemiology. 2015; 26(1):43-50. [DOI:10. 1097/EDE. 0000000000000203] [PMID] [PMCID]

16. Jerrett M, McConnell R, Chang CR, Wolch J, Reynolds K, Lurmann $\mathrm{F}$, et al. Automobile traffic around the home and attained body mass index: A longitudinal cohort study of children aged 10-18 years. Preventive Medicine. 2010; (Suppl. 50):S50-8. [DOI:10. 1016/j. ypmed. 2009. 09. 026] [PMID] [PMCID]

17. Jerrett M, McConnell R, Wolch J, Chang R, Lam C, Dunton $G$, et al. Traffic-related air pollution and obesity formation in children: A longitudinal, multilevel analysis. Environmental Health. 2014; 13:49. [DOI:10. 1186/1476-069X-13-49] [PMID] [PMCID]

18. McConnell R, Shen E, Gilliland FD, Jerrett M, Wolch J, Chang $\mathrm{CC}$, et al. A longitudinal cohort study of body mass index and childhood exposure to secondhand tobacco smoke and air pollution: The Southern California Children's Health Study. Environmental Health Perspectives. 2015; 123(4):360-6. [DOI:10. 1289/ehp. 1307031] [PMID] [PMCID]

19. Alderete TL, Habre R, Toledo-Corral CM, Berhane K, Chen Z, Lurmann FW, et al. Longitudinal associations between am- 
bient air pollution with insulin sensitivity, $\beta$-cell function, and adiposity in Los Angeles Latino children. Diabetes. 2017; 66(7):1789-96. [DOI:10. 2337/db16-1416] [PMID] [PMCID]

20. Fioravanti S, Cesaroni G, Badaloni C, Michelozzi P, Forastiere F, Porta D. Traffic-related air pollution and childhood obesity in an Italian birth cohort. Environmental Research. 2018; 160:479-86. [DOI:10. 1016/j. envres. 2017. 10. 003] [PMID]

21. Fleisch AF, Luttmann-Gibson $H$, Perng $W$, Rifas-Shiman SL, Coull BA, Kloog I, et al. Prenatal and early life exposure to traffic pollution and cardiometabolic health in childhood. Pediatric Obesity. 2017; 12(1):48-57. [DOI:10. 1111/ijpo. 12106] [PMID] [PMCID]

22. Borenstein M, Hedges LV, Higgins JPT, Rothstein HR. Introduction to meta-analysis. New York: John Wiley and Sons; 2009.

23. Peterson RA, Brown SP. On the use of beta coefficients in meta-analysis. Journal of Applied Psychology. 2005; 90(1):175-81. [DOI:10. 1037/0021-9010. 90.1. 175] [PMID]

24. Mazidi M, Speakman JR. Ambient particulate air pollution (PM2. 5) is associated with the ratio of type 2 diabetes to obesity. Scientific Reports. 2017; 7(1):9144. [DOI:10. 1038/ s41598-017-08287-1] [PMID] [PMCID]

25. Stieb DM, Chen L, Eshoul M, Judek S. Ambient air pollution, birth weight and preterm birth: A systematic review and meta-analysis. Environmental Research. 2012; 117:100-11. [DOI:10. 1016/j. envres. 2012. 05. 007] [PMID]

26. Li X, Huang S, Jiao A, Yang X, Yun J, Wang Y, et al. Association between ambient fine particulate matter and preterm birth or term low birth weight: An updated systematic review and meta-analysis. Environmental Pollution. 2017; 227:596-605. [DOI:10. 1016/j. envpol. 2017. 03. 055] [PMID]

27. Dong GH, Qian ZM, Liu MM, Wang D, Ren WH, Flick LH, et al. Ambient air pollution and the prevalence of obesity in Chinese children: The seven northeastern cities study. Obesity. 2014; 22(3):795-800. [DOI:10. 1002/oby. 20198]

28. McConnell R, Gilliland FD, Goran M, Allayee H, Hricko A, Mittelman $S$. Does near-roadway air pollution contribute to childhood obesity? Pediatric Obesity. 2016;11(1):1-3. [DOI:10. 1111/ijpo. 12016] [PMID] [PMCID]

29. Vrijheid M, Casas M, Gascon M, Valvi D, Nieuwenhuijsen M. Environmental pollutants and child health-a review of recent concerns. International Journal of Hygiene and Environmental Health. 2016; 219(4-5):331-42. [DOI:10. 1016/j. ijheh. 2016. 05. 001] [PMID]

30. Toledo-Corral C, Alderete T, Habre R, Berhane K, Lurmann $F$, Weigensberg $M$, et al. Effects of air pollution exposure on glucose metabolism in Los Angeles minority children. Pediatric Obesity. 2018; 13(1):54-62. [DOI:10. 1111/ijpo. 12188] [PMID] [PMCID]
31. Kelishadi R, Mirghaffari N, Poursafa P, Gidding SS. Lifestyle and environmental factors associated with inflammation, oxidative stress and insulin resistance in children. Atherosclerosis. 2009; 203(1):311-9. [DOI:10. 1016/j. atherosclerosis. 2008. 06. 022] [PMID]

32. Zou MH. Is NAD (P) H oxidase a missing link for air pollution-enhanced obesity? Arteriosclerosis, Thrombosis, and Vascular Biology. 2010; 30(12):2323-4. [DOI:10. 1161/ATVBAHA. 110. 216648] [PMID] [PMCID]

33. Xu X, Yavar Z, Verdin M, Ying Z, Mihai G, Kampfrath T, et al. Effect of early particulate air pollution exposure on obesity in mice: Role of p47phox. Arteriosclerosis, Thrombosis, and Vascular Biology. 2010; 30(12):2518-27. [DOI:10. 1161/ATVBAHA. 110. 215350] [PMID] [PMCID]

34. Sun Q, Yue P, Deiuliis JA, Lumeng CN, Kampfrath T, Mikolaj $\mathrm{MB}$, et al. Ambient air pollution exaggerates adipose inflammation and insulin resistance in a mouse model of diet-induced obesity. Circulation. 2009; 119(4):538-46. [DOI:10. 1161/CIRCULATIONAHA. 108. 799015] [PMID] [PMCID]

35. Liu C, Xu X, Bai Y, Wang TY, Rao X, Wang A, et al. Air pollution-mediated susceptibility to inflammation and insulin resistance: Influence of $\mathrm{CCR}_{2}$ pathways in mice. Environmental Health Perspectives. 2014; 122(1):17-26. [DOI:10. 1289/ehp. 1306841] [PMID] [PMCID]

36. Hajat A, Diez-Roux AV, Adar SD, Auchincloss AH, Lovasi GS, O'Neill MS, et al. Air pollution and individual and neighborhood socioeconomic status: Evidence from the Multi-Ethnic Study of Atherosclerosis (MESA). Environmental Health Perspectives. 2013; 121(11-12):1325-33. [DOI:10. 1289/ ehp. 1206337] [PMID] [PMCID]

37. Fram MS, Ritchie LD, Rosen N, Frongillo EA. Child experience of food insecurity is associated with child diet and physical activity. The Journal of Nutrition. 2015; 145(3):499-504. [DOI:10. 3945/jn. 114. 194365] [PMID]

38. Krebs NF JM, American academy of pediatrics committee on nutrition. Prevention of pediatric overweight and obesity. Pediatrics. 2003; 112(2):424-30. [DOI:10. 1542/peds. 112. 2. 424] [PMID]

39. Bourdeaudhuij I, Lefevre J, Deforche B, Wijndaele K, Matton L, Philippaerts R. Physical activity and psychosocial correlates in normal weight and overweight 11 to 19 year olds. Obesity. 2005; 13(6):1097-105. [DOI:10. 1038/oby. 2005. 128] [PMID]

40. Trost SG, Kerr L, Ward DS, Pate RR. Physical activity and determinants of physical activity in obese and non-obese children. International Journal of Obesity. 2001; 25(6):8229. [DOI:10. 1038/sj. ijo. 0801621] [PMID]

41. Nerriere É, Zmirou-Navier D, Blanchard O, Momas I, Ladner J, Le Moullec $Y$, et al. Can we use fixed ambient air monitors to estimate population long-term exposure to air pollutants? The case of spatial variability in the Genotox ER study. Environmental Research. 2005; 97(1):32-42. [DOI:10. 1016/j. envres. 2004. 07. 009] [PMID] 


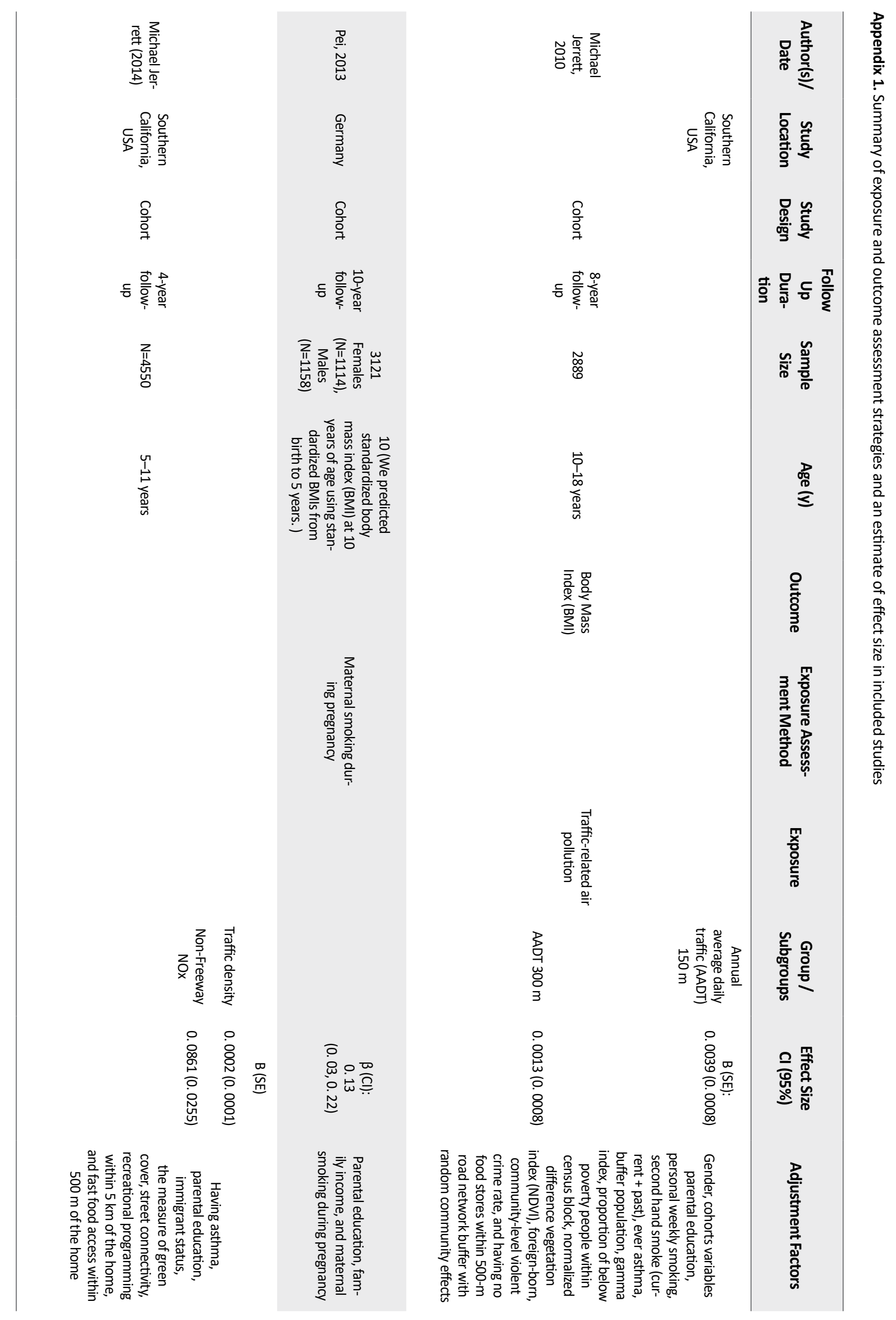




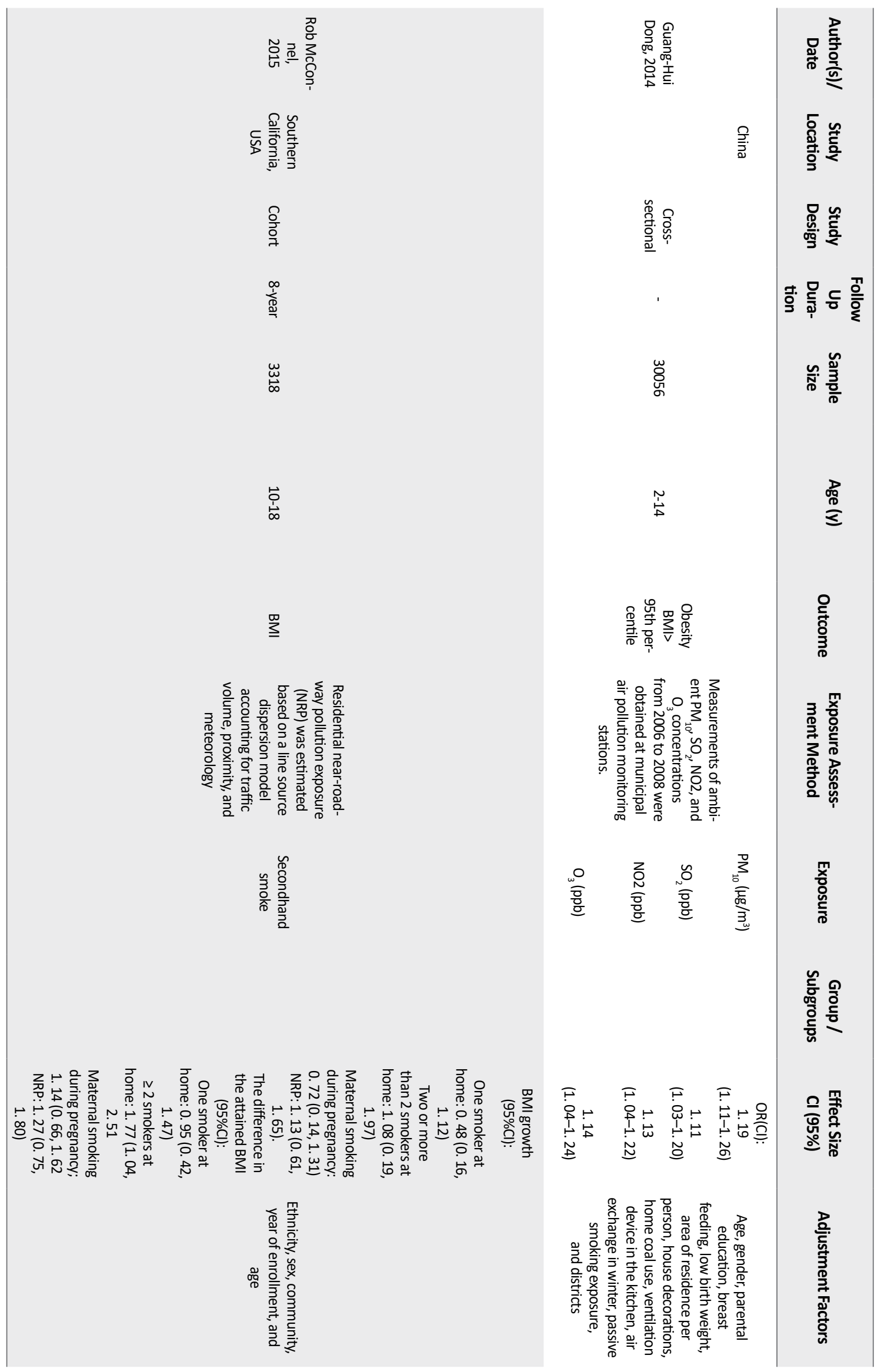




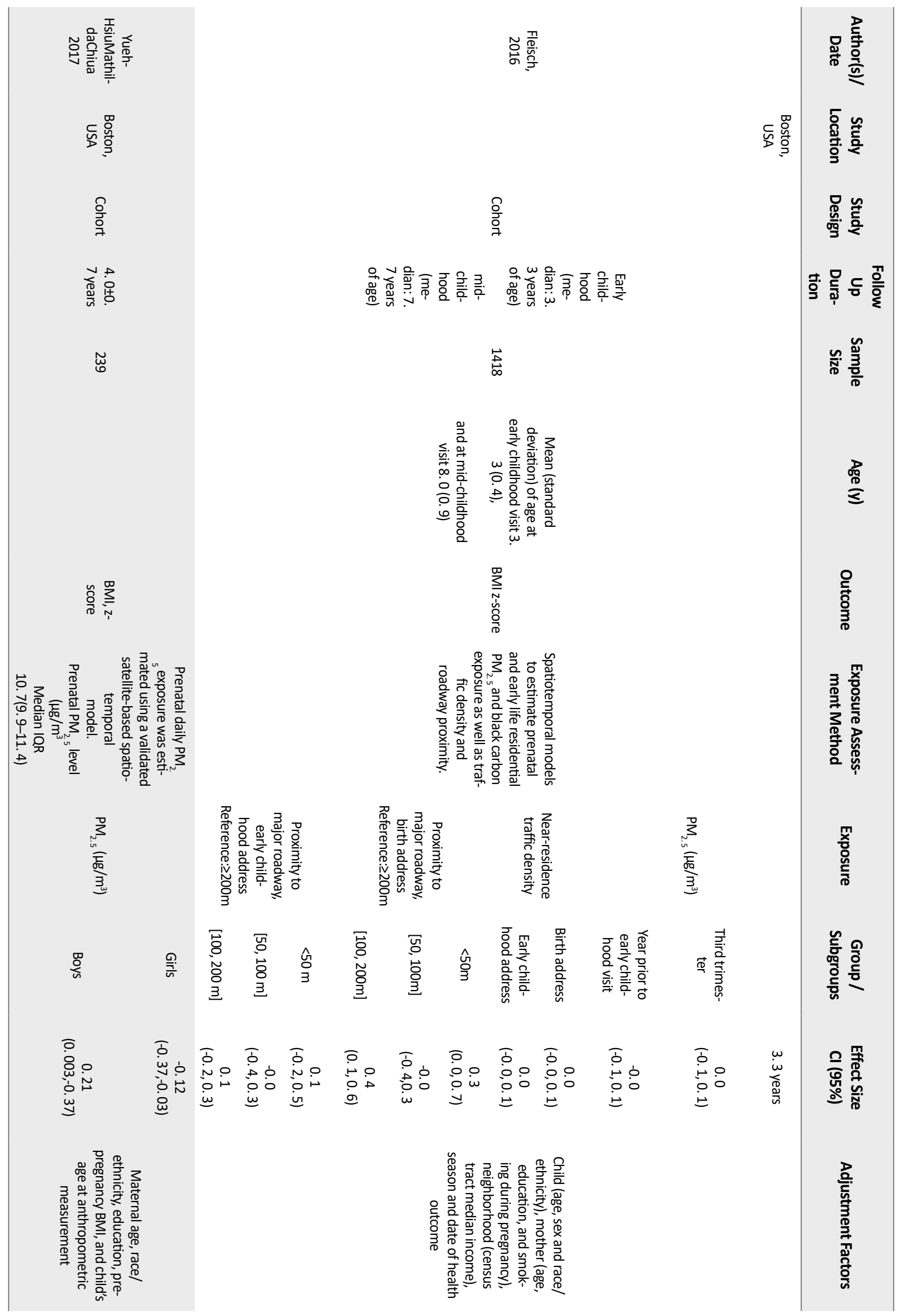




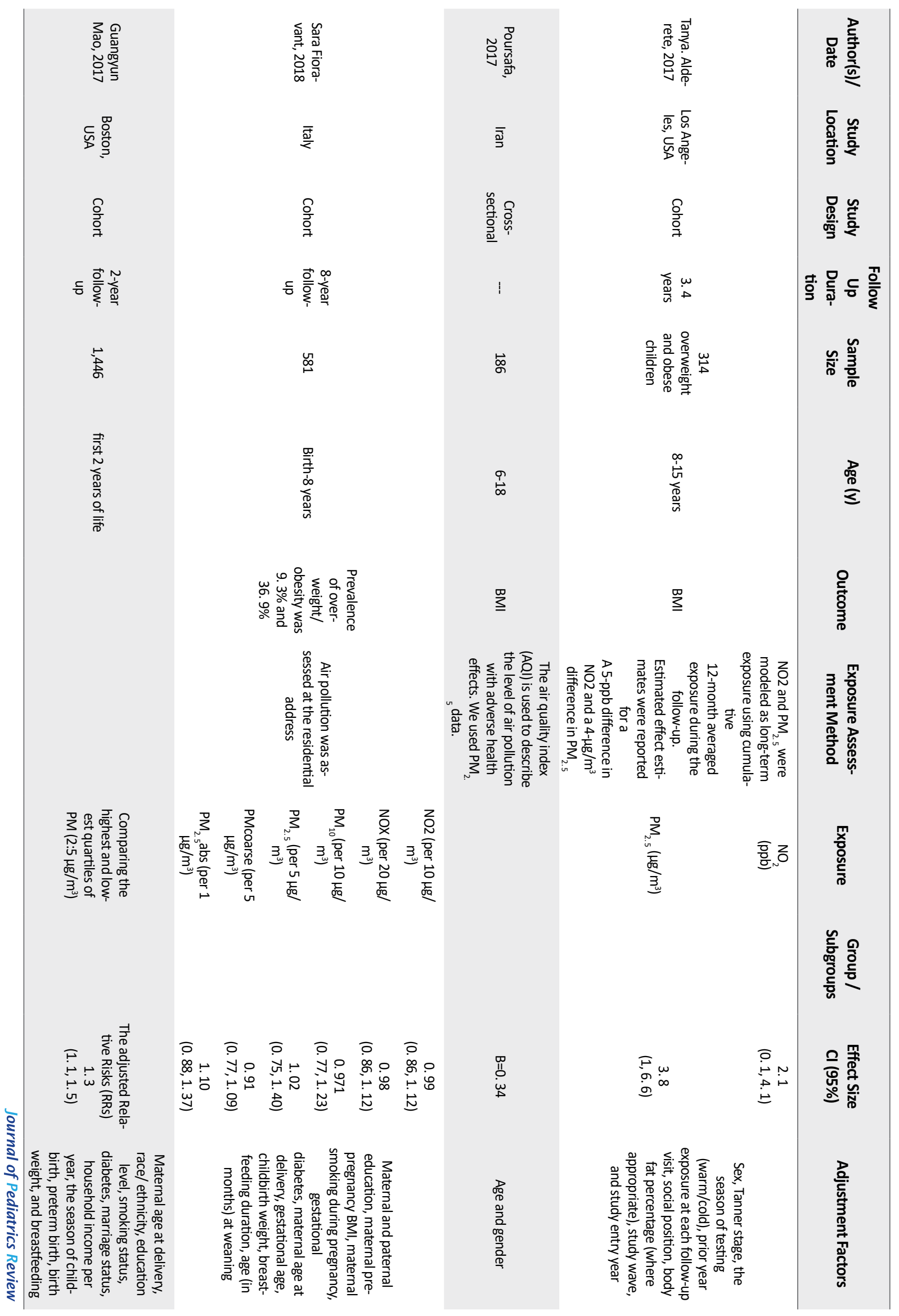


This Page Intentionally Left Blank 